\title{
MUNDO PERCEPTÍVEL, MENTE E LINGUAGEM: UMA LEITURA A PARTIR DE THOMAS REID
}

\author{
Perceptive world, mind and language: from Thomas Reid's view
}

Jacson Jonas Faller*

Resumo: Na filosofia moderna, Thomas Reid (1710-1796) foi um dos filósofos que olhou com atenção para o problema da vagueza das palavras quando utilizadas para expressar nosso pensamento ao outro. Ao tratar da concepção de linguagem, Reid parece abordar o tema da ambiguidade e da vagueza das palavras de modo a afastar os erros que a linguagem carrega consigo, apurando-a no sentido de torná-la mais adequada à representação dos fenômenos mentais e, desta forma, tornar possível o avanço sobre o estudo acerca da mente. O presente estudo busca tornar aparente a noção reidiana de linguagem, pretendendo, assim, expor o que esta noção pode representar no que diz respeito à relação entre mundo perceptível, mente e linguagem a partir do pensamento de Reid.

Palavras-chave: Thomas Reid. Linguagem. Mente. Mundo.

\begin{abstract}
In modern philosophy, Thomas Reid (1710-1796) was one of the philosophers who has looked carefully at the matter of the vagueness of words when used to express our thoughts to others. With regard to his conception of language, Reid seems to address the ambiguity and vagueness of words to avert errors that language carries and thus making the representation of mental phenomena more suitable so as to advance on the study of the mind. This study seeks to unveil Reidian theory of language, aiming at expounding the ways this notion may represent the relationship among the perceptible world, mind and language from Thomas Reid's View.
\end{abstract}

Keywords: Thomas Reid. Language. Mind. World

\footnotetext{
* Mestre em Filosofia pelo Programa de Pós-Graduação em Filosofia da Pontifícia Universidade Católica do Rio Grande do Sul (PUCRS). PRÓ-BOLSAS PUC/RS. Contato: jacsonfaller@terra.com.br
}

\begin{tabular}{|c|c|l|l|l|l|}
\hline intuitio & $\begin{array}{c}\text { ISSN } \\
1983-4012\end{array}$ & Porto Alegre & Vol.7 $-\mathrm{N}^{\mathrm{o}} .1$ & $\begin{array}{c}\text { Junho } \\
2014\end{array}$ & p.139-156 \\
\hline
\end{tabular}




\section{Introdução}

Há um consenso entre os estudiosos de linguagem nas diferentes áreas de conhecimento que linguagem como instrumento é aquilo que utilizamos para nos comunicarmos. Contudo, é-nos conhecida a ideia que a linguagem como expressão do pensamento possa se mostrar insuficiente para expressar nosso conteúdo mental com precisão. Nota-se que, por vezes, o pensamento parece surgir já em forma de expressões, noutras, percebe-se que ocorre algo de "nebuloso", e tão somente depois disto reformulamo-los em expressões. E é exatamente neste ponto que a linguagem, tomada como instrumento, pode manifestar sua precariedade, as palavras podem revelar sua vagueza. Uma situação típica a ser citada como exemplo poderia ser a da expressão de nossas respostas emocionais aos objetos e eventos. Nós podemos usar a língua para explicar nossa reação aos outros, mas a reação em si, como sentencia D. Crystal, "vai além das palavras"1. No entanto, é-nos vedada a negação que haja uma comunicação satisfatória. Falantes de língua entendem-se, compartilham informações, testemunham, manifestam seus desejos; em resumo, comunicam seu conteúdo mental ao outro.

Na filosofia moderna, Thomas Reid (1710-1796) foi um dos filósofos que olhou com atenção para o problema da vagueza das palavras quando utilizadas para expressar nosso pensamento ao outro. Tratando-se da concepção de linguagem, Reid parece abordar o tema da ambiguidade e da vagueza das palavras de modo a afastar os erros que a linguagem carrega consigo, apurando-a no sentido de tornála mais adequada à representação dos fenômenos mentais e, desta forma, tornar possível o avanço sobre o estudo acerca da mente. Para isto, Reid propõe que façamos uma análise das, por assim dizer, origens da linguagem. Sua busca é por um uma melhoria ${ }^{2}$ da linguagem no que diz respeito à representação de nossos conteúdos mentais; ou, já na terminologia reidiana, de nossas operações da mente.

Contemporâneo de Kant, Reid abordou problemas caros à filosofia de sua época, como, por exemplo, a concepção de senso comum relacionado ao conhecimento do mundo exterior e as questões que concernem às tendências céticas de seus antecessores. Para tal, teve como interlocutores outros grandes nomes da filosofia moderna, principalmente Hume (1771-1776) e Berkeley (1685-1753), bem como as obras de Locke (1632 -1704). Contudo, fora com Berkeley que Reid teve, segundo Lehrer ${ }^{3}$, inspiração para dissertar sobre a teoria dos signos, a compreensão de linguagem natural e a visão de linguagem como meio de tornar pública a compreensão do mundo perceptível. Entre as semelhanças, as opiniões dos dois sobre a natureza da percepção de objetos externos e a refutação do ceticismo, principalmente, em se tratando de Reid, o ceticismo atribuído ao sistema filosófico de Hume. No entanto, Reid e Berkeley divergiram acerca da concepção de ideia, objeto de discórdia e de muita discussão entre os filósofos modernos; a rejeição de Reid ao que ele chamou de "caminho das ideias"

${ }^{1}$ CRYSTAL, D. The Cambridge Encyclopedia of Language. Cambridge: Cambridge University Press, 2010, p.14.

${ }^{2}$ REID, 2000, p. 51.

${ }^{3}$ LEHRER, 2002, p. 7. 
(the way of ideas) é uma das mais conhecidas no âmbito da comunidade de pesquisa em filosofia. E, é a partir desta crítica que Reid passa a conceber seu próprio sistema, conhecido como a escola escocesa do senso comum ${ }^{4}$.

\section{A Linguagem para Thomas Reid}

Os modos linguísticos de expressar o pensamento humano podem ser quase que infinitos: há os poetas, os lógicos, as pessoas no seu dia-a-dia, os advogados nos tribunais, e tudo mais que se possa imaginar como sendo plausível em seres humanos sensatos e ativos intelectualmente. No entanto, o arcabouço de linguagem usado por cada um destes indivíduos é o mesmo. Quase tudo que pode ser dito em uma língua pode também ser dito nas demais. Embora as palavras nem sempre encontrem equivalência exata entre os idiomas existentes, o sentido do que é dito permanece o mesmo. Segundo R. Pich ${ }^{5}$, para Reid, "a atenção à estrutura da linguagem se justifica para o propósito de pesquisa porque a linguagem é expressiva dos pensamentos e das operações da mente" ${ }^{6}$. Escreve Pich":

[D]ado que há precedência dos estados mentais com respeito aos fenômenos de fala, pode-se afirmar que, se operações mentais afins não fossem comuns à humanidade, não seria possível encontrar nas linguagens existentes "formas de discurso pelas quais elas são expressas" - formas de discurso, leia-se, semelhantes. Não se propõe uma correspondência perfeita entre mente e linguagem; por certo, o que pode haver na e ser distinguido através da mente humana é mais extenso do que aquilo que pode ser expresso e distinguido na linguagem "comum".

Ocorre que, para Reid, há entre os ensinamentos do senso comum e a estrutura da linguagem comum um elo demasiadamente estreito para que não o levemos em consideração. Ele toma a linguagem comum como sendo o "espelho" dos nossos pensamentos cotidianos. Reid parte do pressuposto de que há certas estruturas comuns a todas as linguagens que derivam da constituição natural da mente humana ${ }^{8}$. $\operatorname{Reid}^{9}$, corroborando a favor da ideia de que comunicação do pensamento é a principal função da linguagem e de que a linguagem é, antes, pensamento, de forma sucinta, porém incisiva, define linguagem como sendo todos os sinais que o homem usa para comunicar seus pensamentos e intenções aos outros ${ }^{10}$, e demarca a linguagem em duas grandes classes de sinais, os sinais artificiais e os sinais naturais ${ }^{11}$.

\footnotetext{
${ }^{4}$ A respeito da ideia de senso comum em Thomas Reid e a sua influência na filosofia anglo-saxônica: PICH, R. "A Filosofia do Senso Comum de Thomas Reid e o 'Critical Comun-sensism' de C. S. Peirce". In: Cognitio, São Paulo, v.13, n.2, jul./dez., 2012, pp. 279-299.

${ }_{5}^{5}$ PICH, R. "Thomas Reid, O Método De Filosofar e a Rejeição do Ceticismo". In: DISSERTATIO Revista de Filosofia, Pelotas \#32, verão/ 2010a, pp. 243 - 275.

${ }^{6} \mathrm{PICH}, 2010$ a, p. 256.

${ }^{7}$ PICH, 2010a, p. 256.

${ }^{8}$ REID, 2002, pp. 56-57.

${ }^{9}$ REID, 2000, p. 51.

${ }^{10}$ REID, 2000, p. 51.

${ }^{11}$ REID, 2000, p. 51.
}

\begin{tabular}{|c|c|c|c|c|c|}
\hline intuitio & $\begin{array}{c}\text { ISSN } \\
1983-4012\end{array}$ & Porto Alegre & Vol.7 $-\mathrm{N}^{\circ} .1$ & $\begin{array}{l}\text { Junho } \\
2014\end{array}$ & p.139-156 \\
\hline
\end{tabular}


Desta forma, os sinais artificiais são caracterizados por resultarem de um acordo por parte de quem os utiliza, e o significado destes sinais artificiais é aquele que fora estabelecido por esse acordo. Já os sinais naturais são aqueles que todas as pessoas previamente conhecem o seu significado, não por um acordo, mas pelos princípios da sua natureza. O objetivo de Reid é demonstrar que antes de qualquer linguagem artificial, é necessário que tenha existido uma linguagem natural, pois só esta pode fornecer os sinais necessários a uma linguagem artificial. A favor disto, Reid argumenta que há algumas noções que são partilhadas por todos os povos. É-nos fácil notar que, para Reid, a força da linguagem não reside nos sinais artificiais, mas, antes, nos sinais naturais. Segundo Reid, dois selvagens sem linguagem artificial podem conversar, isto é, podem comunicar seus pensamentos um ao outro ${ }^{12}$. Portanto, são os sinais naturais que possibilitam, originalmente, a comunicação de nossos pensamentos. Segundo Reid, à medida que o homem vai utilizando mais e mais a linguagem artificial, vai, ao mesmo tempo, deteriorando a linguagem natural, passa a gradativamente substituir a linguagem natural por uma artificial, quando o melhor seria, no entanto, voltar sua atenção à linguagem natural.

\subsection{Sinais naturais e sinais artificiais}

A mente humana é um tópico complexo, mas podemos, sem entrar em grandes detalhes e complexidades, atentarmos aos nossos próprios pensamentos, pensamentos estes que se dão instantaneamente no cotidiano, nos nossos afazeres do dia-a-dia. Independentemente se acerca de assuntos filosóficos ou relacionados a algum compromisso doméstico, é praticamente impossível que possamos saber com certeza o modo como ocorrerá devido às infinitas variedades de pensamentos. Disto, é-nos possível supor que, assim como a construção de uma língua perfeita é impossível, não é possível conceber uma linguagem que represente com precisão a vida mental consciente. É neste sentido que a linguagem continua a ter um papel fundamental na busca da clarificação dos conteúdos mentais, principalmente porque, visto que sua estrutura, de acordo com Reid, possui em sua forma algo de semelhante a das sensações. Para Reid, as nossas sensações são sinais naturais.

Reid, de acordo com R. Nichols ${ }^{13}$, coloca sua argumentação acerca das sensações a serviço de sua teoria dos sinais naturais. Em certas circunstâncias, continua Nichols, uma careta ou até mesmo a impressão que um objeto nos causa na retina, pode ser um sinal natural que venha a formar um conceito perceptual (perceptual concept). Ver uma careta pode nos fazer crer que o sujeito está sentindo uma dor física, a impressão na retina pode significar ser um sinal natural que nos sugira formar um conceito perceptual; uma impressão na retina pode significar a figura visível de um objeto de percepção. Portanto, conclui Nichols, há diferentes categorias de sinais naturais e, em cada categoria, há um tipo diferente de input que irá nos submeter a um tipo diferente de output, muito

${ }^{12}$ REID, 2002, p. 52.

${ }^{13}$ NICHOLS, R. Thomas Reid's Theory of Perception. New York: Oxford University Press, 2007, 317 p.

\begin{tabular}{|c|c|l|l|l|l|}
\hline intuitio & $\begin{array}{c}\text { ISSN } \\
1983-4012\end{array}$ & Porto Alegre & Vol.7 $-\mathrm{N}^{\mathrm{o}} .1$ & $\begin{array}{c}\text { Junho } \\
2014\end{array}$ & p.139-156 \\
\hline
\end{tabular}


embora todos os outputs sejam cognoscíveis ${ }^{14}$. As línguas foram feitas para servir aos propósitos da conversação ordinária, e não temos nenhuma razão para esperar que ela deva fazer distinções que não sejam de senso comum ${ }^{15}$. Porém, todas as linguagens possuem imperfeições, alerta-nos Reid:

[E]las nunca serão adequadas a todas as variedades do pensamento humano, por isso, pode acontecer que duas coisas sejam realmente distintas em sua natureza, podendo ser assim distinguidas pela mente humana, embora não possam ser distinguidas na linguagem comum. O máximo que podemos esperar encontrar na estrutura das línguas são as distinções que toda a humanidade tem necessidade de constatar nos assuntos comuns da vida ${ }^{16}$.

O que Reid parece propor é apenas uma pequena "atenção" à língua no que se refere ao vocabulário mental. Uma rápida correção de nossa linguagem, por exemplo, já poderia ajudar a distinguir melhor as sensações dos objetos mesmos. Com mínimas alterações nas formas de nossas expressões linguísticas logo observaríamos significativas melhoras na comunicação de nossos pensamentos. Conforme Reid as "operações da mente, a partir de sua própria natureza, levam a mente a dar atenção a outro objeto" ${ }^{17}$. Reid não tem dúvidas que as nossas sensações "são sinais naturais, e voltam nossa atenção às coisas significadas por eles; tanto que a maioria deles, e entre os mais frequentes e familiares, não têm nenhum nome em qualquer língua"18.

Um exemplo conhecido é a proposta feita por Reid acerca da descrição da experiência subjetiva da dor. A expressão "estar dolorido" é uma expressão que tem a função de mostrar como a língua artificial poderia ser alterada para representar com maior eficiência os eventos mentais. Como utilizamos as mesmas expressões para classificar sensações e percepções, acabamos por confundi-las como sendo de mesma natureza. Seu argumento é que a expressão "sinto uma dor" pode parecer implicar que a sensação é algo distinto da dor sentida, contudo, na realidade, não há distinção. Reid propõe uma expressão mais fiel ao evento mental da dor: "estar dolorido". Justifica esta alteração afirmando que tal como "pensar um pensamento" é uma expressão que não poderia significar mais do que "pensar", "sentir uma dor" não significa mais do que "estar dolorido". O que Reid afirma com esta argumentação é que não se tem uma dor como se possui um objeto exterior; então, é necessário reformular a nossa expressão linguística para podermos expressar de forma mais fiel nossas operações mentais. Portanto, quando sentimos uma dor, a melhor forma de expressá-la não é afirmar que se tem uma dor, e sim, que se está dolorido. Tão somente desta forma se pode eliminar a distinção que parece existir, pois quando estamos doloridos não podemos dizer que a dor que sentimos é diferente da sensação que temos dela, porque são uma e a mesma coisa ${ }^{19}$.

\footnotetext{
${ }^{14}$ NICHOLS, 2007, p. 86.

${ }^{15}$ REID, 2002, p. 194.

${ }^{16}$ REID, 2002, p. 56.

${ }^{17}$ REID, 2002, p. 60.

${ }^{18}$ REID, 2002, p. 61.

${ }^{19}$ REID, 2000, p. 168 .
}

\begin{tabular}{|l|c|l|l|l|l|}
\hline intuitio & $\begin{array}{c}\text { ISSN } \\
1983-4012\end{array}$ & Porto Alegre & Vol.7- $\mathrm{N}^{\mathrm{o}} .1$ & $\begin{array}{c}\text { Junho } \\
2014\end{array}$ & p.139-156 \\
\hline
\end{tabular}


Assim como Berkeley, Reid ilustra sua teoria das sensações como sinais, usando uma analogia entre palavras e sensações. É importante notar, entretanto, segundo R. Copenhaver ${ }^{20}$, que Reid considera palavras e sensações como significando o que significam diretamente. Reid nota que quando lemos uma palavra não atentamos à palavra, mas ao seu sentido. Analogamente, quando percebemos, não atentamos à sensação, mas ao objeto apresentado na percepção. Pois, para Reid, as sensações do olfato, paladar, som e cor são infinitamente de maior importância como sinais ou indicações do que são em sua própria consideração; assim como as palavras de uma língua, nas quais não atentamos ao som, mas ao sentido. No ato da sensação a mente está voltada para o objeto, e não à sensação. De acordo com Reid, sensações significam objetos independentemente de nossa atenção ou consciência deles. Os sentimentos de toque, que sugerem qualidades primárias ${ }^{21}$, não têm nomes, tampouco são sempre pensados. Eles atravessam a mente instantaneamente e servem apenas para introduzir a noção e a crença das coisas externas, que pela nossa constituição, são conectados com eles. Eles são sinais naturais, e a mente passa imediatamente para a coisa significada sem fazer reflexão alguma sobre o sinal ou a observação de que há alguma coisa ${ }^{22}$.

$\mathrm{Na}$ filosofia de Reid é a linguagem natural que fornece os sinais necessários à linguagem artificial. De acordo com esta prioridade da linguagem natural para com a artificial, uma linguagem artificial pressupõe o entendimento de linguagem natural. Deste modo, a aquisição de um sinal artificial já implica um acordo entre as pessoas. Os sinais naturais são anteriormente necessários para o nosso conhecimento dos pensamentos dos outros e pressupostos para a aprendizagem de uma língua artificial. A fim de formar os acordos necessários para uma linguagem artificial é preciso haver concordância entre as partes, e, de antemão, saber o que pensam e pretendem. Ou seja, antes de qualquer coisa, para tornar possível que estipulemos que a palavra $x$ signifique $y$, é necessário que saibamos, antes, por intermédio da compreensão de linguagem natural, o que passa na mente do outro. Não obstante, de todos os elementos da linguagem natural do homem, Reid se concentra apenas em três tipos: modulações da voz, gestos e expressões ${ }^{23}$. São estes os elementos que se conservam e que permitem a comunicação entre povos diferentes. Segundo Reid, quando a fala é natural, quando envolve não apenas o uso da voz e dos pulmões, mas também de todos os músculos do corpo, nosso discurso é, consequentemente, mais expressivo e de mais fácil entendimento. Reid ainda vai além defendendo que os sinais artificiais significam, mas não expressam. As paixões, afeições e desejos só podem ser realmente expressos pelos sinais naturais; os artificiais apenas falam ao entendimento. Se subtrairmos os sinais artificiais da conduta humana, ainda sim, os homens serão capazes de

${ }^{20}$ COPENHAVER, R. "Thomas Reid's Direct Realism". In: Reid Studies, vol. 4, n. 1, 2000, pp. 17-34.

${ }^{21}$ Exemplos de qualidades primárias de um objeto externo são extensão, divisibilidade, figura, movimento, solidez, dureza, maciez e fluidez. (REID, 2002, p. 97).

${ }^{22}$ COPENHAVER, 2000, p. 23.

${ }^{23}$ REID, 2000, pp. 51-52.

\begin{tabular}{|c|c|l|l|l|l|}
\hline intuitio & $\begin{array}{c}\text { ISSN } \\
1983-4012\end{array}$ & Porto Alegre & Vol.7 $-\mathrm{N}^{\mathrm{o}} .1$ & $\begin{array}{c}\text { Junho } \\
2014\end{array}$ & p.139-156 \\
\hline
\end{tabular}


comunicação, utilizando todos os sinais naturais possíveis para se fazerem entender ${ }^{24}$. Segundo Lehrer, a teoria dos sinais naturais de Reid é uma teoria dos princípios inatos da mente ${ }^{25}$ :

O primeiro tipo de princípio inato é o que conecta as coisas na mente como resultado de serem unidas na experiência e faz de uma o sinal da outra. O segundo tipo de princípio inato conecta as coisas na mente antes de serem ligadas na experiência e fazem de uma o sinal da outra. O terceiro sinal de princípio inato não só conecta as coisas na mente antes da experiência e faz de uma o sinal da outra, mas também gera a nossa primeira concepção da coisa significada. A distinção entre o segundo e terceiro tipo de sinais reflete uma diferença no problema da mente dos outros e o problema do mundo externo. No caso das mentes dos outros, temos uma concepção da percepção mental da nossa consciência delas. O problema não é o de obter uma concepção de operações mentais dos outros. É o de determinar que comportamento dê significado às operações em que as operações da mente dos outros são 'invisíveis' para nós. Aqui a natureza supre a relação entre o sinal e o que ele significa como resultado de um primeiro princípio. No caso de o mundo externo, existe o problema de se obter uma concepção dos objetos externos e suas qualidades primárias, bem como o de determinar o que dá significado à existência de tais objetos e qualidades. Aqui a natureza supre nossa primeira concepção de objetos externos e as qualidades primárias por um primeiro princípio, bem como fornece a conexão entre o sinal e o que ela significa desta forma.

Para Reid a linguagem natural demanda um conhecimento inato referente à conexão entre o sinal e o objeto sinalizado. Conexão esta que se estabelece, principalmente, por intermédio de três classes de sinais naturais. A primeira classe sugere que a conexão entre, em uma linguagem mais contemporânea, signo e significado é estabelecida naturalmente, porém revelada apenas através da experiência. A segunda classe é aquela em que a conexão entre signo e significado se dá naturalmente, não sendo necessário raciocínio ou experiência. Já a terceira compreende aqueles sinais que, embora não se tenha nenhuma noção prévia sobre a coisa significada, criam naturalmente, como por mágica ${ }^{26}$, uma concepção ou crença sobre a coisa significada. A partir destes princípios inatos, Reid conclui que a conexão entre nossas sensações e a concepção e a crença dos objetos externos não pode ser produzida por hábito, tampouco por experiência ou aprendizagem, mesmo que invariavelmente conectadas. E, por isso, esta conexão é efeito da nossa constituição e deve ser considerada como princípio original da natureza humana. A linguagem original é natural, anterior a qualquer convenção linguística, e os seres humanos são naturalmente aptos a interpretar estes sinais da linguagem natural ${ }^{27}$, linguagem esta já capacitada para expressar nossos pensamentos. Em se tratando da linguagem artificial, se não a esclarecermos, apenas obscurecerá o que se passa em nossa mente.

\section{Operações da Mente}

Reid admite que, assim como da essência do corpo, da essência da mente nada ou pouco sabemos. No entanto, afirma que do corpo nos é possível definir certos atributos, ao passo que, da

\footnotetext{
${ }^{24}$ REID, 2000, pp. 52-53.

${ }^{25}$ LEHRER, 2002, p. 45.

${ }^{26}$ LEHRER, 2002, p. 60.

${ }^{27}$ REID, 2000, p. 191.
}

\begin{tabular}{|c|c|l|l|l|l|}
\hline intuitio & $\begin{array}{c}\text { ISSN } \\
1983-4012\end{array}$ & Porto Alegre & Vol.7 $-\mathrm{N}^{\circ} .1$ & $\begin{array}{l}\text { Junho } \\
2014\end{array}$ & p.139-156 \\
\hline
\end{tabular}


mente, estamos autorizados a falar de suas operações $^{28}$. Na concepção de Reid, mente é tudo aquilo que podemos considerar como pensar. De acordo com sua concepção, a mente é um ente, por natureza, ativo; e operação da mente é todo e qualquer modo de pensar do qual estamos, ou somos, conscientes $^{29}$, ou seja, toda e qualquer atividade intelectual consciente é uma operação.

Uma das grandes contribuições de Reid para os estudos da mente e da linguagem foi ter percebido que as operações da mente são sociais. Como esclarece A. Leclerc ${ }^{30}$, Reid trouxe a ideia que nem todas as operações da mente independem do ambiente social ${ }^{31}$. Para Reid, tudo aquilo que nos é possível saber sobre a mente humana implica vida e energia ativa; e, é a partir desta implicação que todos os seus modos de pensar são chamados de operações; operações estas que, em sua maioria, não são meramente passivas como o corpo é, mas são realmente e propriamente ativas ${ }^{32}$. E é exatamente por intermédio destes poderes e faculdades que Reid acaba por explicar as características da vida mental.

De acordo com Reid, toda consciência é já autoconsciência. Se penso, sei que estou pensando, sei de meus próprios pensamentos, como também sei o significado das sentenças que profiro. Reid afirma, de acordo com Pich, que "uma noção distinta sobre as operações pressupõe como condição necessária uma consciência delas" ${ }^{\prime 3}$. Para Reid é preciso atentar às operações enquanto estão ocorrendo e refletir cuidadosamente assim que são executadas, ainda frescas em nossa memória ${ }^{34}$. Para isso, é necessário fazer uso do poder de reflexão através do qual a mente se volta a ela mesma e observa suas ações e operações, permitindo que possamos ter noções distintas do nosso poder ou do poder do outro ${ }^{35}$.

Reid compreende que todo homem é consciente de suas operações da mente, porém são poucos aqueles que refletem sobre estas operações ou fazem delas seu objeto de pensamento, dando atenção geralmente ao objeto externo sobre o qual essas operações acontecem e não às operações mesmas. Reid sugere ainda que a atenção é um ato voluntário que requer um esforço para ser iniciado e ter continuidade, cuja duração depende do desejo de quem a utiliza; e, muito mais do que isso, precisa ser desenvolvida por exercício, prática. Até que se crie o hábito de atentar para as operações da nossa própria mente não será possível distinguir suas noções, tampouco julgá-las com precisão ${ }^{36}$. Então, algo além de atenção às operações se faz necessário para se descobrir a verdade no que diz respeito a essas operações ${ }^{37}$.

\footnotetext{
${ }^{28}$ REID, 2002, p. 20.

${ }^{29}$ REID, 2002, pp. 20-21.

${ }^{30}$ LECLERC, A. "Operações sociais da mente". In: Veritas, v. 55, n. 2, 2010, pp. 108-125.

${ }^{31}$ LECLERC, 2010, p. 120.

${ }^{32}$ REID, 2002, pp. 20-21.

${ }^{33} \mathrm{PICH}, 2010 \mathrm{a}$, p. 254.

${ }^{34}$ REID, 2000, p. 96.

${ }^{35}$ REID, 2002. p. 58.

${ }^{36}$ REID, 2002. p. 59.

${ }^{37}$ REID, 2002, p. 61.
} 
Para um maior entendimento da distinção feita por Reid entre as operações da nossa mente, pontua-se que, concordando com Coady, Reid pensa a expressão por intermédio da linguagem falada como intrinsecamente orientada para a comunicação e como necessitando de formação simbólica; muito embora, Reid não concorde que as linguagens artificiais, "incluindo aquelas muitas vezes chamadas de linguagens naturais para distingui-las de sistemas formais simbólicos, sejam a única forma que a linguagem pode tomar" ${ }^{\prime 38}$. Segundo o pensamento de Reid, um homem pode ter entendimento e vontade. Ele pode apreender, julgar e raciocinar, ainda que não tenha conhecimento de nenhum ente inteligente no universo além dele mesmo ${ }^{39}$. Mas, em outras operações se percebe que é necessário que haja outra mente inteligente para que estas operações se deem, como, por exemplo, prometer e testemunhar ${ }^{40}$.

\section{Testemunho}

Quando filósofos usam a palavra testemunho, conforme R. Audi ${ }^{41}$, geralmente eles têm em mente "qualquer instância de alguém dizendo alguma coisa a outro". Em outras palavras, testemunho é o tipo de coisa pela qual se aprende fatos ditos por outro ser inteligente; ou ainda, num sentido mais amplo, testemunho aplica-se a quase tudo que nós dizemos aos outros. Infelizmente não há espaço no presente trabalho para maiores e mais detalhadas discussões a respeito deste tópico acerca da aquisição de conhecimento. No entanto, para que se continue com a investigação sobre a concepção reidiana de linguagem subjacente à sua teoria das operações da mente e a relação entre mundo, mente e linguagem é necessário que se trate, aos moldes e à visão de Reid, a questão da confiabilidade e do valor do testemunho.

Para Reid, os objetos do conhecimento humano são inúmeros, mas os canais pelos quais são transmitidos são poucos. Entre eles, Reid dá atenção à percepção das coisas externas pelos nossos sentidos e às informações que recebemos pelo testemunho humano. Segundo Reid, no testemunho humano, dado pela linguagem falada, as coisas são significadas por meio de sinais, e em cada um deles a mente passa, seja por princípios originais ou por costume, do sinal à concepção e à crença das coisas significadas ${ }^{42}$. F. Müller ${ }^{43}$ pondera que pessoas invariavelmente não aprendem a falar ou a pensar sem a ajuda de outros. Ainda de acordo com Müller, muitas das crenças de uma pessoa dependem pelo menos em parte do testemunho de alguém ${ }^{44}$.

\footnotetext{
${ }^{38}$ COADY, 2004, p.184.

${ }^{39}$ REID, 2002, p. 69.

${ }^{40}$ REID, 2002, p. 68.

41 AUDI, R. "Testimony, Credulity, and Veracity". In: LACKEY, J; SOSA, E. (Ed.). The epistemology of testimony. Oxford : Clarendon Press, 2006, pp. 25-49.

42 REID, 2000, p. 190.

${ }^{43}$ MÜLLER, F. "Conhecimento Testemunhal: A Visão Não Reducionista". In: Veritas, v. 55, n. 2, 2010, pp. 126-143.

${ }^{44}$ MÜLLER, 2010, pp. 126-127.
}

\begin{tabular}{|c|c|c|c|c|c|}
\hline intuitio & $\begin{array}{c}\text { ISSN } \\
1983-4012\end{array}$ & Porto Alegre & Vol.7 $-\mathrm{N}^{\mathrm{o}} .1$ & $\begin{array}{c}\text { Junho } \\
2014\end{array}$ & p.139-156 \\
\hline
\end{tabular}


Em Reid lemos que o testemunho sempre será expresso linguisticamente ante outro ente inteligente e capacitado para a compreensão desta expressão. Por linguisticamente deve-se entender como por intermédio da linguagem artificial, principalmente, por intermédio da linguagem falada. Reid defende que o testemunho é um ato social e essencialmente expresso por palavras e $\operatorname{signos}^{45}$. Para uma melhor ilustração, nota-se que Reid propõe que um testemunho tácito é uma contradição, enquanto um juízo tácito é apenas um erro que não fora expresso em palavras. Logo, um falso testemunho é uma mentira, ao passo que um juízo errôneo é apenas um erro ${ }^{46}$. Muito embora, Coady ${ }^{47}$ nos chame a atenção quanto à opacidade desta sustentação, pois lemos em Reid, segundo Coady, duas afirmações altamente dúbias ${ }^{48}$. Na primeira afirmação, Reid alega que o testemunho não expressa juízo; na segunda, assegura que a expressão pública de uma opinião científica ou crítica não é testemunho, mas expressão de juízo ${ }^{49}$. Porém, certo é que, na argumentação reidiana, a função primordial da linguagem é expressar as operações sociais da mente por intermédio do testemunho, e não a de expressar juízos, que são atos solitários da mente. A expressão linguística de um juízo não é o próprio juízo. O juízo mesmo é uma operação solitária da mente ${ }^{50}$. Deste modo, a partir da ideia que em todas as línguas o testemunho e o juízo são expressos pela mesma forma de discurso e que tanto proposições afirmativas ou negativas são expressas por verbos no modo indicativo, Reid conclui que para sabermos a intenção daquele que nos fala sempre atentaremos ao assunto e às circunstâncias, e, assim, poderemos facilmente ver se um homem pretende dar o seu testemunho ou meramente expressar o seu juízo, não a partir da escolha de sua forma de discurso.

No entanto, considerando a semelhança da linguagem utilizada por nós para expressarmos tanto juízos quanto testemunho e o postulado que é apenas segundo as circunstâncias e os assuntos que saberemos a diferença entre essas expressões, cabe que indaguemos: como é e o que garante que aquilo que nos falam é confiável e certo ou meramente equívocos intelectuais ou mentiras grotescas? Ou melhor, o que nos garantiria (e nos faria crer) na comunicação de um testemunho por intermédio da linguagem artificial, que a palavra do outro é digna de confiança? Para tal, Reid formula dois princípios que convenciona chamar de principio de veracidade (the principle of veracity) e princípio de credulidade (the principle of credulity). Estes princípios são, como expõe Cleve ${ }^{51}$, elementares para que entendamos satisfatoriamente o pensamento de Reid acerca do testemunho humano. Ou, como lemos nas palavras de Cleve, "estes princípios são os elementos-chave em sua [de Reid] consideração

\footnotetext{
${ }^{45}$ REID, 2002, p. 407.

${ }^{46}$ REID, 2002, p. 407.

${ }^{47}$ COADY, C. A. J. Testimony: A Philosophical Study. Oxford: Clarendon, 1992. 315 p.

${ }^{48}$ COADY, 1992, p. 56.

${ }^{49}$ REID, 2002, pp. 406-407.

${ }^{50}$ REID, 2002, p. 407.

${ }^{51}$ CLEVE, J. "Reid on the Credit of Human Testimony". In: LACKEY, J; SOSA, E. (Ed.). The epistemology of testimony. Oxford : Clarendon Press, 2006, pp.50-74.
}

\begin{tabular}{|c|c|l|l|l|l|}
\hline intuitio & $\begin{array}{c}\text { ISSN } \\
1983-4012\end{array}$ & Porto Alegre & Vol.7- $\mathrm{N}^{\mathrm{o}} .1$ & $\begin{array}{c}\text { Junho } \\
2014\end{array}$ & p.139-156 \\
\hline
\end{tabular}


de como as palavras dos outros venham a ser sinais que expressam a nós as coisas que não teríamos como saber por nós mesmos" 52 .

\subsection{Veracidade e Credulidade}

Muito antes da composição de seus Essays ${ }^{53}$ (1785), Reid, já no Inquiry ${ }^{54}$, publicado em 1764, havia tratado direta e abertamente sobre o testemunho humano ao que respeita seu papel na aquisição de conhecimento, bem como seus princípios essenciais para o funcionamento da argumentação acerca do testemunho. Segundo F. Müller, Reid considerou de modo efetivo a possibilidade de o testemunho desempenhar um papel epistemológico primário, e não apenas secundário na aquisição de conhecimento. Todavia, esclarece Müller ${ }^{55}$ :

[O] ponto central da abordagem de Reid parece ser a de que ele vê o agente epistêmico em meio a relações sociais. [...] Reid sustentou que o testemunho dos outros - ou, ao menos, o testemunho sincero - é prima facie crível, mesmo quando não se tem razões independentes em favor da confiabilidade da testemunha. Reid pensava que, se as atitudes naturais de confiança mútua não fossem razoáveis, o resultado inevitável seria o ceticismo.

Nenhum homem de senso comum jamais pensou em tomar a própria palavra de um homem por sua honestidade, nos fala Reid, e, segundo sua convicção, é diante da expressão de um testemunho que sempre tomaremos a palavra daquele que nos fala como garantida ${ }^{56}$. Como ponto de partida, no entendimento de Reid, quando começamos a aprender a língua materna, é por intermédio do testemunho do outro que percebemos, através dos sons emitidos pelo outro (modulações de voz, por exemplo) o que aquele que se dirige a nós quer. Do mesmo modo, imitamos os sons ouvidos para que nos façamos entender também ${ }^{57}$, confiando que seremos compreendidos. Há, de acordo com Reid, uma antecipação inicial na mente humana que não deriva nem da experiência nem da razão de que, ainda de acordo com esta concepção, "os nossos semelhantes farão uso dos mesmos sinais na linguagem, quando eles tiverem os mesmos pensamentos" (sentiments). Para Reid, é isto que se configura como um tipo de antevisão em todas as ações humanas e parece ser um princípio original da nossa constituição, sem o qual seríamos incapazes de uma linguagem humana e, consequentemente, de instrução, de aprendizagem ${ }^{58}$.

\footnotetext{
${ }^{52}$ CLEVE, 2006, p. 51.

${ }^{53}$ REID, Thomas. Essays on the Intellectual Powers of Man. A critical edition. Text edited by Derek R. Brookes, annotations by Derek R. Brookes and Knud Haakonssen; introduction by Knud Haakonssen. Pennsylvania: Pennsylvania State University Press, 2002. 651 p.

${ }^{54}$ REID, Thomas. An Inquiry into the Human Mind on the Principles of Common Sense. Edited by Derek R. Brookes. Edinburgh: Edinburgh University, 2000. 345 p.

${ }_{55}^{55}$ MÜLLER, 2010, p. 130.

${ }^{56}$ REID, 2000, p. 192.

${ }^{57}$ REID, 2000, p. 130.

${ }^{58}$ REID, 2000, p. 193.
}

\begin{tabular}{|l|c|l|l|l|l|}
\hline intuitio & $\begin{array}{c}\text { ISSN } \\
1983-4012\end{array}$ & Porto Alegre & Vol.7- $\mathrm{N}^{\mathrm{o}} .1$ & $\begin{array}{c}\text { Junho } \\
2014\end{array}$ & p.139-156 \\
\hline
\end{tabular}


Coady ${ }^{59}$ nos diz que nossa definição de testemunho é naturalmente concentrada naquele que nos fala (que nos testemunha), porém, para termos uma definição completa é necessário que nos concentremos também na interpretação daquele que ouve (ou recebe) o testemunho. Para que se compreenda a argumentação de Reid acerca dos princípios de veracidade e de credulidade, é necessário que se tenha em mente sua defesa de nossa constituição natural. Pois, para Reid, fora o "beneficente autor da Natureza, que fez com que fôssemos criaturas sociais" e que recebêssemos uma grande e importante parte do nosso conhecimento pela informação dos outros, além de ter implantado em nossa natureza dois princípios que se somam: a propensão a falar a verdade e a disposição de confiar na veracidade dos outros, leia-se, o princípio da veracidade e o princípio da credulidade ${ }^{60}$.

A propensão a falar a verdade, na concepção de Reid, possui "uma orientação poderosa, mesmo nos maiores mentirosos; pois, onde eles mentem uma vez, eles falam a verdade uma centena de vezes", uma vez que "a verdade é sempre a mais elevada e é a questão natural da mente"61. É interessante que se note que é necessário que falemos, que expressemos nosso testemunho, para que o outro dê crédito à nossa palavra, à veracidade de nossas palavras; por instinto, sabemos que há uma conexão real formada entre nossas palavras e nossos pensamentos, e "embora essa conexão seja quebrada em toda instância de mentir e equivocar-se, sendo essas instâncias, todavia, comparativamente raras, a autoridade do testemunho humano é somente enfraquecida por elas, mas não destruída"62. Quanto à disposição de confiar na veracidade de outros, Reid defende que há uma credulidade natural (natural credulity). Pondera Reid que este princípio é "ilimitado nas crianças até que elas venham a encontrar instâncias de engano e falsidade: e conserva um grau de força considerável ao longo da vida". Reid ${ }^{63}$ parte da ideia que:

\begin{abstract}
Se a natureza tivesse deixado a mente do falante in equilibrio, sem qualquer inclinação para o lado da verdade mais do que para o da falsidade, as crianças mentiriam tão frequentemente quanto falam a verdade, até que a razão estivesse amadurecida ao ponto de sugerir a imprudência de mentir, ou estivessem conscientes ao ponto de sugerir sua imoralidade. E se a natureza tivesse deixado a mente do ouvinte in equilibrio, sem qualquer inclinação para o lado da crença mais do que para o da descrença, não tomaríamos [como verdadeira] a palavra de homem nenhum até que tivéssemos evidência positiva de que ele falou a verdade.
\end{abstract}

Nessa suposição as crianças seriam, de acordo com Reid, absolutamente incrédulas; e, desta forma, portanto, seriam incapazes de qualquer tipo de aprendizagem. Vale que se note uma vez mais que o fato de crermos na palavra dos outros, na argumentação reidiana, não deriva de nosso raciocínio e tampouco da experiência, pois, conforme Reid, se credulidade fosse o efeito de raciocínio e de experiência, ela deveria crescer e reunir força na mesma proporção que a razão e a experiência fazem. Todavia, se é o caso da credulidade ser mesmo um princípio, se ela é um dom da natureza, será mais

\footnotetext{
${ }^{59}$ COADY, 1992, p. 46.

${ }^{60}$ REID, 2000, pp. 193-194.

${ }^{61}$ REID, 2000, p. 193.

${ }^{62}$ REID, 2000, p. 194.

${ }^{63}$ REID, 2000, p. 194.
}

\begin{tabular}{|l|c|l|l|l|l|}
\hline intuitio & $\begin{array}{c}\text { ISSN } \\
1983-4012\end{array}$ & Porto Alegre & Vol.7- $\mathrm{N}^{\mathrm{o}} .1$ & $\begin{array}{c}\text { Junho } \\
2014\end{array}$ & p.139-156 \\
\hline
\end{tabular}


forte e limitada na infância e restrita pela experiência; a visão mais superficial da vida humana mostra que o último é realmente o caso, e não o primeiro $^{64}$. Deste modo, a disposição de confiar na veracidade dos outros na infância é ilimitada; na medida em que crescemos, ela se restringe. As crianças ${ }^{65}$, por exemplo, confiam nas declarações, nas promessas e no testemunho dos outros antes mesmo que saibam o que é ou o que significa a palavra "promessa".

\section{A Linguagem na Relação Mundo Perceptível e Mente}

O gênero humano, por intermédio dos sinais naturais e de sua capacidade de invenção e de razão ${ }^{66}$, cria a linguagem artificial, cuja criação se dá pela necessidade de expressar seus pensamentos a seus semelhantes. Seu pensamento sobre o mundo externo advém de suas sensações e de suas percepções dos objetos externos. Independentemente de seus juízos acerca deste mundo, os homens, por necessidade de comunicação, percebem que algumas de suas operações da mente, na concepção de Reid, não são apenas operações solitárias, mas, antes, sociais. O testemunho que é transmitido por intermédio da linguagem artificial, bem como o uso desta linguagem artificial, é um ato social. De acordo com Coady ${ }^{67}$, segundo Reid, a função primordial da linguagem é a de expressar operações da mente que são sociais. Dado que é através da linguagem que o ser humano expressa seus pensamentos e as operações da mente, e que há precedência dos estados mentais com respeito aos fenômenos de fala, Reid toma a linguagem comum como sendo o espelho dos nossos pensamentos cotidianos.

A fim de uma melhor compreensão, nota-se que, como Cleve aponta ${ }^{68}$, "há uma analogia extraordinária entre o testemunho dado pelos sentidos da natureza humana e o testemunho dos seres humanos dado pela linguagem - uma analogia tão grande que é natural que se use a palavra 'testemunho' em ambos os casos"69. Segundo Coady, "o ponto básico da analogia entre percepção e testemunho é que ambos envolvem a operação de sinais e que os sinais operam em cada caso de modos similares"70. Tal analogia foi dividida por Reid em dois grupos: algumas percepções são naturalmente dadas, percepções originais; outras são dadas apenas por intermédio da experiência e não

\footnotetext{
${ }^{64}$ REID, 2000, pp. 194-195.

65 Como contraponto vale notar que os estudos de Noam Chomsky sobre a aquisição da linguagem e a competência linguística demonstraram que, por mais pobres que sejam os estímulos vindos do meio, toda criança aprende a falar muito cedo e é capaz de formular corretamente frases que jamais ouviu antes. Para Chomsky, há um inatismo na linguagem: não importa em qual língua a criança seja criada nem quanto esforço os adultos circundantes dediquem a educá-la, ela sempre aprende a dominar o código com total competência. Para explicar esse paradoxo. BIZZOCCHI, A. "A "Língua" do Pensamento". In: Revista da Língua Portuguesa, ano 7, n. ${ }^{\circ}$ 75, janeiro de [2012]. Disponível em: < http://www.aldobizzocchi.com.br/artigo110.asp>. Acessado em: 13 de Outubro de 2013.

${ }^{66}$ REID, 2000, p. 50.

${ }^{67}$ COADY, C. A. J. "Reid on Testimony". In DALGARNO, M.; MATTHEWS, E. (eds.). The Philosophy of Thomas Reid. Dordrecht: Kluwer Academic Publishers. 1989, pp. 225-246.

${ }^{68}$ CLEVE, James Van. "Reid on the Credit of Human Testimony". In: LACKEY, J; SOSA, E. (Ed.). The epistemology of testimony. Oxford : Clarendon Press, 2006, pp.50-74.

${ }^{69}$ CLEVE, 2006, p. 54.

${ }^{70}$ COADY, 1989, p. 232.
}

\begin{tabular}{|c|c|l|l|l|l|}
\hline intuitio & $\begin{array}{c}\text { ISSN } \\
1983-4012\end{array}$ & Porto Alegre & Vol.7 $-\mathrm{N}^{\mathrm{o}} .1$ & $\begin{array}{c}\text { Junho } \\
2014\end{array}$ & p.139-156 \\
\hline
\end{tabular}


ocorreriam se não houvesse, antes, as percepções naturais, percepções adquiridas. Com a linguagem, analogamente, ocorre o mesmo. A linguagem artificial requer contratos, e contratos não poderiam ser instituídos pelas criaturas se não houvesse uma linguagem de algum tipo. Então, tem que haver linguagem natural para que se criem outras. Da mesma maneira, pode-se dizer que uma linguagem artificial, uma vez inventada, não pode ser aprendida a menos que haja sinais naturais de apoio e discórdia ${ }^{71}$ :

Nos quatro fenômenos a serem considerados (percepções originais, linguagem natural, percepções adquiridas e linguagem artificial) há sinais e coisas significadas, e a mente vai de uma apreensão do sinal à crença na coisa significada. As várias similaridades e diferenças que Reid nota concernem à origem da relação entre sinal e coisa significada e os meios pelos quais viemos saber esta relação.

Deste modo, os sinais na percepção original são sensações. E, se são sensações, Cleve pondera que é por um princípio inato que nossa mente vai da apreensão do sinal à coisa significada ${ }^{72}$. Para Reid, "a natureza estabeleceu a conexão entre o sinal e a coisa significada e nos ensinou a interpretação de um sinal antes de qualquer experiência"73. Entretanto, já nas percepções adquiridas, os sinais são tanto sensações quanto as coisas que percebemos por meio das sensações. Cleve expõe que a "conexão entre o sinal e a coisa significada é estabelecida pela Natureza. Mas, neste caso devemos descobrir a conexão através da experiência e indução". Assim, há algumas coisas que devemos aprender (adquirir), e tais coisas "não estão escritas na nossa constituição". Porém, basta que aprendamos o sinal para que ele automaticamente sugira a coisa significada, "é quase como se 'víssemos' o que aprendemos"74. Coady nos coloca que "não inferimos a natureza e a existência das competências da propriedade da natureza da sensação já que não há semelhança entre elas”. Em vez disso, passamos da sensação ao juízo perceptual através da operação de um princípio particular de nossa constituição ${ }^{75}$. Sobretudo se, ainda de acordo com Coady, considerarmos que o que Reid nos apresenta forçando a analogia entre testemunho e percepção é uma imagem do conhecimento baseado no testemunho.

Conforme Reid, "nossas percepções adquiridas e a informação que recebemos por meio da linguagem artificial devem ter resolução em princípios gerais da constituição humana"76. $\mathrm{Na}$ linguagem artificial os sinais são sons articulados cuja conexão com as coisas significadas por eles é estabelecida pelo desejo do homem: aprendendo nossa língua materna descobrimos esta conexão por experiência. De tal modo, dado que nossas percepções originais são poucas se comparadas às adquiridas e dado que sem as percepções originais não teríamos possibilidade de chegarmos às percepções adquiridas, igualmente, sem linguagem natural não haveria como se ter chegado à criação

\footnotetext{
${ }^{71}$ CLEVE, 2006, p. 55.

${ }^{72}$ CLEVE, 2006, p. 55.

${ }^{73}$ REID, 2000, p. 191.

${ }^{74}$ CLEVE, 2006, pp. 55-56.

${ }^{75}$ COADY, 1989, p. 232

${ }^{76}$ REID, 2000, p. 191.
}

\begin{tabular}{|c|c|c|c|c|c|}
\hline intuitio & $\begin{array}{c}\text { ISSN } \\
1983-4012\end{array}$ & Porto Alegre & Vol.7- $\mathrm{N}^{\mathrm{o}} .1$ & $\begin{array}{c}\text { Junho } \\
2014\end{array}$ & p.139-156 \\
\hline
\end{tabular}


de uma linguagem artificial. Nos sons articulados da linguagem artificial temos a conexão com as coisas significadas. De acordo Pich ${ }^{77}$ :

\begin{abstract}
[H]á um sentido em que o contato com o mundo exterior, na percepção, nada mais é que a concepção pela mente de um objeto existente, em regra acompanhada de sensação, respectiva ao uso dos órgãos sensórios - que sofrem a impressão dos objetos do mundo exterior -, e com a realização de um juízo perceptual de existência. Essa crença, além disso, é básica ou imediata: ela não se deve a nenhum tipo de raciocínio ou argumentação, e a sua verdade evidente não é devida inferencialmente a nenhuma outra proposição e a nenhum outro princípio. A confiança nos sentidos para se obter uma crença verdadeira, imediata e evidente sobre o mundo exterior existente e presente está garantida pelo caráter naturalmente não falacioso das operações mentais humanas, e isso equivale a um primeiro princípio do senso comum ou tomado por garantido. Um juízo perceptual tem verdade evidente sobre o seu objeto enquanto tipo de operação mental, e a origem definitiva de sua evidência é um princípio primeiro do senso comum sobre a própria percepção. Esse mesmo não é, para Reid, uma proposição da qual a outra é derivada, mas um princípio constitutivo - como semelhantemente o são outros princípios do senso comum respectivamente às demais operações mentais - daquilo que é o desempenho natural apropriado (não falacioso) do tipo específico de conhecimento que se convenciona chamar de "percepção".
\end{abstract}

As faculdades mentais, no pensamento de Reid, são essencialmente capazes de nos propiciar contato imediato com a realidade, pois não há necessidade de um objeto intermediário para que se perceba ou pense sobre algo. Os objetos externos nos proporcionam percepções e sensações e ao mesmo tempo nos fornecem uma concepção ${ }^{78}$ e uma crença irresistível na existência destes objetos externos $^{79}$. Por percepção Reid toma a concepção e a crença que a natureza produz por intermédio dos sentidos, e por sensação o sentimento que acompanha nossas percepções. Uma sensação é uma consequência mental da influência do objeto sendo percebido ${ }^{80}$. Para todas as sensações não há objeto distinto do ato da mente pela qual é sentido ${ }^{81}$. No entanto, as sensações, diferentemente da percepção, não são propensas a erro. A aparência das coisas para os olhos, argumenta Reid, sempre corresponde às leis fixas da natureza; então, se falarmos apropriadamente, não haverá falácia nos sentidos. A percepção não implica exercício de raciocínio. Das conclusões mais óbvias tiradas de nossas percepções, por raciocínio, chegamos àquilo que se entende por compreensão comum, "pelas quais os homens se conduzem nos assuntos comuns da vida, e pelas quais são distinguidos dos idiotas" ${ }^{22}$.

Os seres humanos expressam operações sociais da mente por intermédio da linguagem. Nossas operações mentais, nossos pensamentos, na concepção de Reid, são pensamentos sobre as percepções

${ }^{77}$ PICH, R. "Thomas Reid sobre Concepção, Percepção e Relação Mente-Mundo Exterior". In: Veritas, v. 55, n. 2, maio/ago. 2010b, pp. 144-175.

${ }^{78}$ De acordo com Pich, a concepção "é um ato mental e diz respeito a um objeto, existente (uma pessoa real) ou não (um cavalo alado); ela supõe um sujeito cognoscente e tem termo em um objeto distinto do ato mental. Neste estudo importa, é claro, a concepção com a qual a percepção pode concorrer de coisas reais do mundo exterior. Ao conceber, a mente tem ou pode ter como termo objetos materiais do mundo exterior, ela termina ou pode terminar em objetos imaginários". (PICH, 2010b, p. 160).

${ }^{79}$ REID, 2002, p. 210.

${ }^{80}$ REID, 2002, p. 210.

${ }^{81}$ REID, 2002, p. 194.

${ }^{82}$ REID, 2002, p. 173.

\begin{tabular}{|c|c|l|l|l|l|}
\hline intuitio & $\begin{array}{c}\text { ISSN } \\
1983-4012\end{array}$ & Porto Alegre & Vol.7 $-\mathrm{N}^{\circ} .1$ & $\begin{array}{c}\text { Junho } \\
2014\end{array}$ & p.139-156 \\
\hline
\end{tabular}


que tiramos diretamente do mundo. E como as sensações acompanham as percepções, tanto as originais quanto as adquiridas, expressamos também, por intermédio da linguagem, as nossas sensações. Acessamos e permitimos acesso ao conteúdo mental por intermédio da palavra do homem, em qualquer língua existente, pois, as características sintáticas da linguagem são comuns por serem constitutivas da humanidade. Por intermédio da linguagem artificial explicamos o mundo (aquilo que tomamos como "verdadeiro") ao outro. No pensamento reidiano, todas as línguas possuem palavras muito bem ajustadas para se conhecer a mente e, como podemos através das características da nossa própria mente conhecer a mente do outro e seus "conteúdos", podemos ter acesso ao conteúdo mental do outro, assim como permitir o acesso ao nosso, ao nosso próprio conteúdo mental; embora não salvo de certos equívocos. Pois, nos termos de Reid, as percepções originais e adquiridas, que temos pelos sentidos, são a linguagem natural do homem, que, em muitos aspectos, tem uma grande afinidade com as línguas humanas. As instancias que temos das percepções adquiridas sugerem esta afinidade, que, como nas línguas humanas, ambiguidades são frequentemente encontradas; então, esta linguagem da natureza nas nossas percepções adquiridas não está isenta delas ${ }^{83}$. Porém, se atentarmos ao nosso vocabulário mental, podemos expressar sempre nosso pensamento através da palavra humana, leia-se, de nossa linguagem oral. Reid nos coloca que em razão de as palavras gerais serem, em alto grau, necessárias à linguagem, deve-se concluir que é necessário que haja concepções gerais, das quais elas são os sinais $^{84}$ :

As palavras são sons vazios quando não significam os pensamentos do falante, e é só a partir de sua significação que elas são nomeadas gerais. Toda palavra que é falada, considerada apenas como um som é um som individual. E só pode ser chamada de uma palavra geral, porque o que ela significa é geral. Agora, aquilo o que isso significa, é concebido pela mente tanto do falante quanto do ouvinte, se a palavra tem um significado distinto, e é bem compreendida. Portanto, é impossível que as palavras possam ter significação geral, a menos que haja concepções na mente do falante e do ouvinte, de coisas que são gerais.

Para Reid, palavras de uma língua devem ser divididas em dois grupos: palavras gerais e nomes próprios. Por nome próprio, Reid compreende todos os nomes que significam um indivíduo único, tais como: nomes de homens, rios, cidades, etc.; isto é, todas as criaturas de Deus ou obra humana que escolhemos distinguir das outras do mesmo tipo por um nome específico. Já as palavras gerais, para Reid, são todas as outras palavras de uma língua que não são nomes próprios, diferentemente da classificação dada pelos gramáticos, por exemplo, que reduzem as palavras a oito ou nove classes que são chamadas de partes do discurso ${ }^{85}$.

A linguagem é uma roupagem que usamos para explicar o que ocorre na mente: na língua há uma vestimenta para os nossos pensamentos; temos uma visão do pensamento do outro quando este nos fala. Quando um ser humano nos diz "tenho uma ideia disto", ele comunica "tenho uma noção, um

\footnotetext{
${ }^{83}$ REID, 2000, p. 189.

${ }^{84}$ REID, 2002, pp. 359-360.

${ }^{85}$ REID, 2002, p. 354.
} 
pensamento, uma concepção disto". Não nos é necessário que identifiquemos uma ideia como algo com existência própria. A palavra ideia, para Reid, nada mais é que pensamento, um pensamento sobre o objeto exterior. A ideia não é, como em Berkeley, uma coisa real impressa nos homens por Deus; e, os corpos, as coisas sensíveis, não existem apenas porque há uma mente que os percebem ${ }^{86}$. Seguindo a linha de Reid, as ideias, leia-se o pensamento, existem em relação direta ao mundo. A mente age (opera) sempre ante um objeto presentemente existente, e por intermédio da linguagem comunicamos esta relação aos outros, às outras mentes, seja quando testemunhamos fatos do mundo ou expressamos desejos ou paixões. O mental é aquilo que só pode ser apreendido como objeto de uma autoconsciência sob a tutela da atenção dispensada às nossas operações da mente; e, como consequência de nossa constituição natural, sabemos também sobre o funcionamento da mente do outro e temos acesso a ela, da mesma forma que permitimos acesso à nossa, àquilo que sabemos acerca do mundo, pois só podemos acessar na mente do outro o que é já crença, particularmente porque "para haver pensamento, é preciso haver um objeto existente"87; objeto este, capaz de nos proporcionar percepções e sensações e, concomitantemente, fornecer-nos uma concepção e uma crença irresistível $^{88}$ em sua existência.

Deste modo, a linguagem seria, neste contexto, não apenas o elo entre as mentes humanas, mas, ainda, aquilo que surgiu da necessidade natural de comunicação e que possibilitaria, assim, tornar públicas nossas operações da mente ante nossos semelhantes, bem como, permitiria o avanço sobre o estudo acerca da mente humana, o progresso sobre o estudo acerca da mente humana. E, já que é através da linguagem que recebemos grande parte do nosso conhecimento, uma correção da linguagem artificial se torna imprescindível para avançarmos na representação dos fenômenos mentais, propiciando maior clareza e exatidão no que é transmitido ao outro; pois a linguagem pode ser falha, inexata e ambígua. No entanto, uma linguagem extremamente precisa não é possível, como nos coloca Reid, já que o que pode ser expresso por ela é muito menor do que há para ser expresso na mente humana. A linguagem tem sua função primeira de comunicação de nossas operações mentais sociais, mas serve também às operações solitárias já que veste nossos pensamentos. Entretanto, nem sempre a linguagem cumprirá com o papel de comunicar as operações mentais com clareza, tampouco nos permitirá saber sobre a intenção daquele que nos fala. Então, é preciso atentar também ao assunto e às circunstâncias quando se dá a expressão do pensamento. A concepção de linguagem humana para Reid pode ser restringida à linguagem falada, quando tratada como a expressão das nossas operações sociais da mente por intermédio do testemunho. Esta linguagem, chamada por Reid de linguagem artificial, fora criada a partir da linguagem natural. E, por intermédio da linguagem artificial, os homens transmitem a seus semelhantes os ensinamentos acerca do mundo perceptivo, tendo como abertura a este mundo nossas percepções sensórias, bem como a interpretação destas percepções dada

${ }^{86}$ Para uma leitura apurada, ver: DANCY, J.; et. al. (eds.) A Companion to Epistemology. Oxford: Blackwell, 1997, p. 261-264.

${ }^{87}$ PICH, 2010b, p. 168.

${ }^{88}$ REID, 2002, p. 210. 
por intermédio dos sinais naturais. A linguagem falada, portanto, seria o acontecimento concreto da expressão do pensamento e do testemunho humano, dado apenas linguisticamente, a partir de um ato da mente, de percepções diretas, evidentes e imediatas do mundo exterior.

\section{Referências}

AUDI, R. "Testimony, Credulity, and Veracity". In: LACKEY, J.; SOSA, E. (Ed.). The epistemology of testimony. Oxford : Clarendon Press, 2006, pp. 25-49.

BERKELEY, G. Ensaio para uma Nova teoria da Visão e A Teoria da Visão Confirmada e Explicada. (Edição Bilíngue). MARQUES, J. (trad.). Campinas:Editora Unicamp, 2010. 224 p.

BIZZOCCHI, A. "A 'Língua' do Pensamento". In: Revista da Língua Portuguesa, ano 7, n. ${ }^{\circ}$ 75, janeiro de 2012. Disponível em: < http://www.aldobizzocchi.com.br/artigo110.asp>. Acessado em: 04 dez. 2012.

CLEVE, J. "Reid on the Credit of Human Testimony". In: LACKEY, J.; SOSA, E. (Ed.). The epistemology of testimony. Oxford : Clarendon Press, 2006, pp.50-74.

COADY, C. A. J. "Reid and the Social Operations of Mind". In: CUNEO, T. and VAN WOUDENBERG, R. (Eds.). The Cambridge Companion to Thomas Reid. Cambridge: Cambridge University Press, 2004, pp. 180 203.

"Reid on Testimony". In: DALGARNO, M.; MATTHEWS, E. (eds.). The Philosophy of Thomas Reid. Dordrecht: Kluwer Academic Publishers. 1989, pp. 225-246. Testimony: A Philosophical Study. Oxford: Clarendon, 1992. 315 p.

COPENHAVER, R. "Thomas Reid's Direct Realism". In: Reid Studies, vol. 4, n. 1, 2000, pp. 17-34.

CRYSTAL, D. The Cambridge Encyclopedia of Language. Cambridge: Cambridge University Press, 2010. 516 p.

DANCY, J.; et. al. (eds.) A Companion to Epistemology. Oxford: Blackwell, 1997, pp. 261-264.

LACKEY, J.; SOSA, E. (Ed.). The epistemology of testimony. Oxford: Clarendon Press, 2006. 312 p.

LECLERC, A. "Operações sociais da mente". In: Veritas, v. 55, n. 2, 2010, pp. 108-125.

LEHRER, K. Thomas Reid: The arguments of the philosophers. London and New York: Rutledge, 2002. 311 p.

MÜLLER, F. "Conhecimento Testemunhal: A Visão Não Reducionista". In: Veritas, v. 55, n. 2, 2010, pp. 117134.

NICHOLS, R. Thomas Reid's Theory of Perception. New York: Oxford University Press, 2007. 317 p.

PICH, R. "A Filosofia do Senso Comum de Thomas Reid e o 'Critical Comun-sensism' de C. S. Peirce". In: Cognitio, São Paulo, v.13, n.2, jul./dez., 2012, pp. 279-299.

"Thomas Reid, O Método De Filosofar e a Rejeição do Ceticismo". In: DISSERTATIO Revista de

Filosofia, Pelotas, n. 32, 2010a, pp. 243 - 275.

"Thomas Reid sobre Concepção, Percepção e Relação Mente-Mundo Exterior". In: Veritas, v. 55, n. 2, maio/ago. 2010b, pp. 144-175.

PLANTINGA, A. Warrant and Proper Function. New York: Oxford University Press, 1993. 256 p.

PLANTINGA, A., WOLTERSTORFF, N. (eds.). Faith and Rationality: Reason and Belief in God. Notre Dame: University of Notre Dame Press, 1983. 321 p.

REID, Thomas. An Inquiry into the Human Mind on the Principles of Common Sense. Edited by Derek R. Brookes. Edinburgh: Edinburgh University, 2000. 345 p.

Essays on the Intellectual Powers of Man. A critical edition. Text edited by Derek R. Brookes, annotations by Derek R. Brookes and Knud Haakonssen; introduction by Knud Haakonssen. Pennsylvania: Pennsylvania State University Press, 2002. p.651.

WOLTERSTORFF, N. Thomas Reid and the story of epistemology. Cambridge (UK): Cambridge Univ., 2001. $265 \mathrm{p}$.

YAFFE, G.; NICHOLS, R. "Thomas Reid". In: The Stanford Encyclopedia of Philosophy (Winter 2009 Edition), Edward N. Zalta (ed.), Disponível em: <http://plato.stanford.edu/archives/win2009/entries/reid/>. Acessado em 05 Outubro de 2012.

Recebido em: 18/11/2013

Aprovado para publicação em: 14/05/2014

\begin{tabular}{|c|c|l|l|l|l|}
\hline intuitio & $\begin{array}{c}\text { ISSN } \\
1983-4012\end{array}$ & Porto Alegre & Vol.7 $-\mathrm{N}^{\mathrm{o}} .1$ & $\begin{array}{c}\text { Junho } \\
2014\end{array}$ & p.139-156 \\
\hline
\end{tabular}

